\title{
A NEW LOOK AT NASALIZATION IN HAITIAN CREOLE*
}

\author{
Albert Valdman \& Iskra Iskrova \\ Indiana University
}

\section{Introduction}

The status of nasal vowels in Haitian Creole (HC) and in French lexifier creoles in general has been the object of a considerable literature. However, its analysis has remained impervious to various types of phonological approaches. The nasal vowel system of HC has posed two major problems: (1) the determination of the total inventory; (2) the analysis of nasal vowels occurring in the context of adjacent or nearby other nasal segments. There is a further issue that has proven even more untractable: the analysis of nasalization phenomena occurring in the post-posed clitics, the third person singular pronoun $l i$ and the definite determiner la. Even more complex but relatively unexplored by phonologists are nasalization phenomena associated with the possessive pronoun in northern varieties of the language, for example [papãm] alternating with [paparãm] and [papa a mwẽ] 'my father', [dwãm] alternating with [do a mwẽ] 'my back' (Valdman 1978).

The maximal inventory of nasal vowels of $\mathrm{HC}$ comprises five units; its major differences with that of Referential French (RF) is the presence of a pair of high vowels and the absence of the front rounded vowel, see Table (1). There are also significant differences in the phonetic characteristics of the various phonemes that will not be dealt with here.

(1) Nasal vowel inventories of HC and RF

\section{Nasal vowel inventories of HC and RF}

Haitian Creole $\tilde{1}$ $\tilde{\mathrm{e}}$

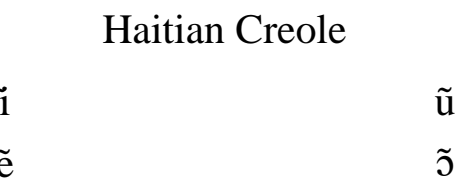

$\tilde{\mathrm{a}}$

\section{Referential French}

$\tilde{\varepsilon} \tilde{\propto}$ $\tilde{\mathrm{o}}$ $\tilde{\mathrm{a}}$

\footnotetext{
*We owe a debt of gratitude to our colleague Stuart Davis who generously provided advice and counsel on theoretical issues; of course, only we as authors are responsible for the application of his suggestions to this specific analysis. We also would like to thank Nicolas André, Lyonèl Jean Desmarattes, and Jacques Pierre who, as native speakers of Haitian Creole, provided some critical examples.
} 
The absence of contrastive pairs have led some linguists to consider the high nasal vowels as allophonic variants (Valdman 1978, Dejean 1980) whereas others arguing from parallel distribution between these vowels and the other three have accorded them phonemic status (Tinelli 1974, Cadely 1994). At this stage of our study we maintain that high vowels may undergo contextual nasalization but we do not have convincing evidence to claim that they are underlyingly nasal.

But the major problem in the treatment of nasal vowels remains their presence in the environment of nasal consonants. Unlike in RF where these vowels are absent before wordfinal nasal consonants (thus [bõ] 'good (masc.)' contrasts with [bon] 'good (fem.)' and sequences like *[bõn] are not permitted), in HC they contrast with oral vowels in that context, see $(2){ }^{1}$

Final Position

\begin{tabular}{|c|c|c|}
\hline a. mo & 'word' & b. nõ \\
\hline pa & 'step' & pã \\
\hline $1 \varepsilon$ & 'hour' & lẽ \\
\hline
\end{tabular}

Preceding a nasal consonant
c. mon 'hill'
d. mõn 'world'
pan 'breakdown' pãn 'to hang'
len 'wool'

In addition, nasal vowels occur in the immediate environment of nasal consonants in word-internal syllables, see (3), and across morpheme boundaries in derivations, as in (4).

lãme 'sea'

(4)

$\begin{array}{lllll}\text { bobin 'spool' } & \text { bobin }+\mathrm{e}> & \text { bobinẽ } & \text { 'to roll up' } \\ \text { gagãn 'throat' } & \text { gagãn }+\mathrm{e}> & \text { gagãnẽ } & \text { 'to hold by the throat' } \\ \text { kapõ } & \text { 'coward' } & \text { kapõn }+\mathrm{e}> & \text { kapõnẽ } & \text { 'to intimidate' } \\ \text { desẽ } & \text { 'drawing' } & \text { desin }+\mathrm{e}> & \text { desinẽ } & \text { 'to draw' }\end{array}$

The pervasive presence of nasal vowels in the environment of nasal consonants has led phonologists to posit general rules of regressive and progressive nasal assimilation (Hall,

\footnotetext{
${ }^{1}$ Note that there are no four-way contrastive pairs involving the front unrounded vowel since [len] and [lẽn] are free variants. The pair [ven] 'our glass' versus [vẽn] 'vein' is minimal but the former member is bimorphenic. ${ }^{2}$ Note that in this form in addition to the nasalization in process there is a vowel quality change that will not be discussed in this paper.
} 
1953, d'Ans 1968, Tinelli 1974). However, not all oral vowels are affected by these putative rules, as shown in the contrastive pairs in (5) and cases of optional nasalization (6).
nẽ 'nose'
mãd 'handle'
ne 'knot'
mal 'step in stairs'

(6)

kotõnad/kotonad 'cotton fabric' fãnal/ fanal 'lantern'

Besides the cases of optional nasalization, there are minimal or near minimal pairs that show a contrast in polysyllabic words, see (7).

\begin{tabular}{|c|c|c|c|}
\hline mãti & 'lie' & mati & 'martyr' \\
\hline chãmst & 'two-story house' & chamo & 'camel' \\
\hline kãnət & 'small boat' & kano & 'shank (of animal)' \\
\hline mõnit & 'computer screen' & monite & 'teaching assistant' \\
\hline
\end{tabular}

In this paper, we will review previous approaches to the analysis of the nasal vowel system of $\mathrm{HC}$, all of which either fail to account for empirical data or violate various theoretical principles of current autosegmental phonological theory. We will then propose an analysis in which, while we return to early solutions that recognized underlying nasal vowels, we remain within an autosegmental framework but also take into account lexical information. In Section 3 of the paper we deal with regressive assimilation and in Section 4 with progressive assimilation. For the sake of economy, we limit that latter section to phenomena occurring word internally, leaving for subsequent research the more thorny issue of progressive assimilation in postposed clitics, notably the third person $l i$ and the definite determiner $l a$, as well as various sandhi phenomena characteristic of northern dialects of $\mathrm{HC}$ (Etienne 1974, Valdman 1978).

2. Existing analysis for regressive assimilation

2.1 The traditional structural analysis

Traditional structural descriptions of the nasal vowel system of HC (Tinelli 1974, Valdman 1978) recognize underlying nasal vowels and posit as well a regressive assimilation rule (8) operating word-internally that would account for the data in (9): 


$$
[\text {-cons }] \rightarrow[+ \text { nas }] / \ldots n C V X
$$

$$
\text { [lãme] 'sea' [mẽna3] 'boy/girl friend' }
$$

A more powerful version of this rule extending the environment to word final syllables has been proposed for Dominican Creole by Taylor (1947) and for HC by d'Ans (1968). In order to prevent the application of the rule to lexemes such as [ $\mathrm{am}]$ 'voodoo charm', resorting to etymological information, these authors invoke a latent post-vocalic $/ \mathrm{r} /$. The presence of that consonant makes Rule (10) no longer applicable, and unlike the contrasting form [ [ãm], the vowel is not nasalized.

$$
[\text {-cons }] \rightarrow[+ \text { nas }] / \ldots n \#
$$

Valdman (1978) provides several empirical and theoretical arguments against this proposal, the most important of which is that the associated rule would be required to delete the post-vocalic /r/ which, furthermore, never surfaces ${ }^{3}$.

\subsection{The problem of variation}

The regressive assimilation rule (7a) is also inadequate because it fails to take into account two empirical facts. As pointed out by Valdman (1978:65) and more recently by Cadely (to appear-a), there is extensive variation in the application of the rule. Three types of cases must be recognized:

(11) a. Obligatory application of the rule: [vẽn] *[ven] 'vein' [lãme] 'wave' (versus [lame] 'old woman')

b. Non application: [pan] 'car breakdown', [kanif] 'penknife'

c. Free variation: [lẽn] $\sim$ [lın] 'wool', [fãnal] [fanal] 'lantern'

\footnotetext{
${ }^{3}$ Another problem with the underlying $r$ hypothesis is that not all etymological $r$ 's block nasalisation, e.g.,

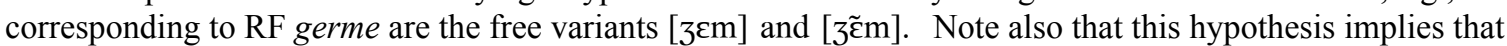
HC lexemes are direct reflexes of RF. As Chaudenson (1992) and Valdman (1992) point out the target accessible to the creators of HC was more likely a variety of non-standard dialects and sociolects of French (regional and vernacular varieties). In some of these, as reflected in present-day overseas varieties of French, post-vocalic $r$ was considerably weakened, if not absent. Furthermore, there exist forms, some cited in Cadely (to appear-b), for which one cannot posit an underlying /r/ and that do not undergo nasalization: e.g., [lapesən] 'person, [bon]'servant'.
} 
As Cadely (to appear-a) underscores, for most lexemes containing the structure XCVNVX the basic lexicographic resources for HC (Valdman et al. 1981, Valdman et al. 1996, Freeman \& Laguerre 1998) list both nasalized and non nasalized variants. A frequency list (Vernet \& Freeman 1988) shows that absence of nasalization dominates: 876 instances versus 498 showing optional nasalization.

\subsection{Previous autosegmental analyses}

Several efforts have been made within an autosegmental framework to account for nasality in HC (Cadely 1994, to appear-a, to appear-b) or Saint Lucian Creole (SLC) (Bhatt and Nikiema 2000). Cadely (to appear-b) has proposed that nasality is derived in HC from a non-associated nasal consonant following the vowel that, by the nasality parameter, is incorporated into the nucleus. Bhatt and Nikiema come up with a similar proposal featuring an adjacent [n]. According to them, an adjacent consonant can only be linked to the rime, and in this particular case to the nucleus.

Cadely's analysis might account for vowel nasalization in French since that language lacks the sequences nasal vowel (V) plus morpheme final nasal consonants $(\mathrm{N})$ displayed in (2d). However, it encounters several problems in accounting for the more complex HC data. In his proposal the underlying representation of [ [ãm] and [kanif] are, respectively, $/ \int \mathrm{a}(\mathrm{n}) \mathrm{m} /{ }^{4}$ and /kanif/. The former (12a) does not contain any skeletal slot for the /n/, whereas the latter (12b) does. When there is no slot (12a), the nasal attaches to the preceding nucleus by the 'nasality parameter' (Prunet, 1992).
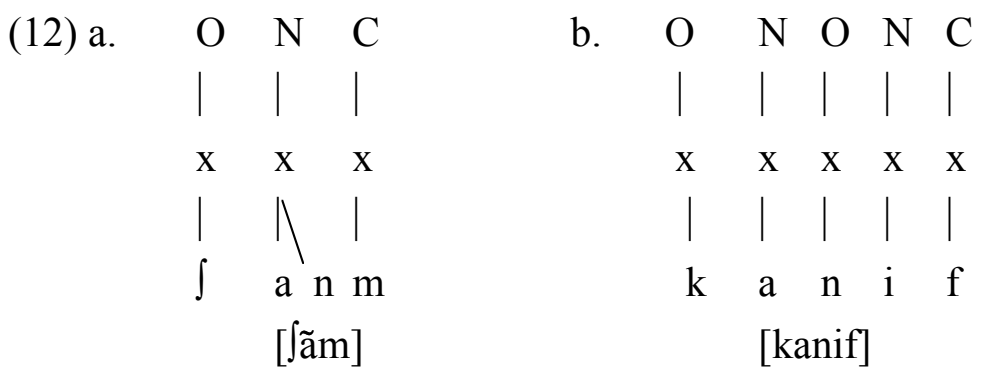

In the case of the doublets ([fãnal] [fanal]) Cadely proposes two possible configurations: with or without linking (13):

\footnotetext{
${ }^{4}$ The parentheses indicate the presence of an $/ \mathrm{n} /$ in the underlying representation that is not anchored in the skeletal structure of the word.
} 
(13) a.

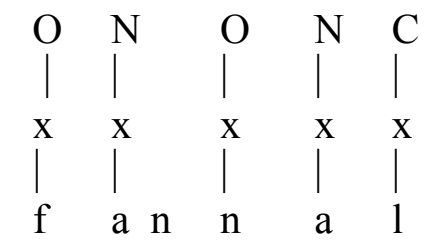

[fanal]

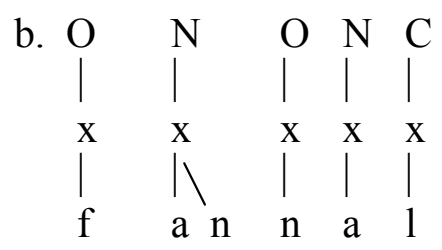

[fãnal]

But (13) does not account completely for the two variants because Cadely does not specify under what conditions the floating /(n)/ is or is not to be associated with the nucleus. What his analysis lacks is some rule or principle governing the modalities of the association and a motivation for the variation.

From a theoretical perspective the representation of [fãnal] as /fa(n)nal/ incurs the violation of two major principles: the Obligatory Contour Principle and the syllabic structure requirements. According to the former (Goldsmith 1976, McCarthy 1988) adjacent identical elements are prohibited. Representations containing two nasals segments in adjacent positions, as is the case for $(/ \mathrm{fa}(\mathrm{n}) \mathrm{nal} /$ and $/ \mathrm{va}(\mathrm{n}) \mathbf{n} /)$, are ruled out by the theory. Adducing evidence from several languages Kaye, Lowenstamm, Vergnaud (1990) show that to be well formed a syllable must adhere to binary branching. The syllable may branch into two rime branches in order to have a nucleus and a coda but it is not allowed to have a branching nucleus within a branching rime. If the underlying representation of [vãn] and [vãt] are, respectively $/ \mathrm{va}(\mathrm{n}) \mathrm{n} /$ and $/ \mathrm{va}(\mathrm{n}) \mathrm{t} /$, then there is a branching nucleus within a branching rime, which constitutes a violation of the syllabic structure requirements (14).

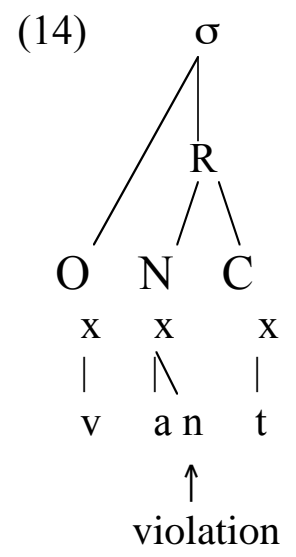


In a more recent analysis Cadely (to appear-a) assigns an underlying status to $\mathrm{HC}$ nasal vowels, but this treatment differs from the previous one only by a terminological variant: naming the floating element a feature rather than a segment. It is not clear what this author means by "nasality is associated with the vowel at the lexical level" ${ }^{5}$; in autosegmental phonology a floating feature is by definition mobile and can associate to various positions within the word, respecting linking and delinking rules. This is not the case in HC, where nasality is associated to one position in particular. The data from the language does not show evidence for the presence of a floating feature.

Concerning the Bhatt \& Nikiema (2000) proposal it does not hold for HC because, unlike in SLC where such pairs as [lãm] and [lam] 'blade' are in free variation, there are contrasts in CVN surface syllables ([โãm] 'room' versus [ [am] 'charm'). There are also theoretical problems that we will not discuss here ${ }^{6}$.

\subsection{Toward an alternative analysis: biconstituency of underlying nasal vowels} We propose that vocalic nasality is both underlying and derived in HC. Although autosegmental analyses have shown a marked preference for derived nasality, we claim that the complex HC data we present here provide sufficient evidence for the need to posit underlying V 's. We follow Paradis and Prunet (2000) who argue that V 's are underlying in French, as well as in Hindi and Portuguese. They claim that, although V's do not have longer durations than oral vowels, they are biconstituent, but at the root level rather than the segmental level. As shown in (15) these vowels consist of one segment with two root nodes: one of them carries the features of the vowel, the second one bears the nasality feature.

\footnotetext{
${ }^{5}$ Our translation of the author's statement: "la nasalité est associée à la voyelle au niveau lexical"

${ }^{6}$ These authors derive the nasality feature by default from the feature specification of the segment. It is indeed the case that the status of nasality is the subject of controversy among autosegmental phonologists but most consider that nasality holds an autonomous node at the root level. Another theoretical problem stems from these authors invoking Government Theory wherein syllables have no branching rimes and codas are replaced by onsets preceding empty nuclei. In their derivation of [3ãm] and [vjãn] (2000:39), they seem to suggest, erroneously in our opinion, that the syllable structure is part of the underlying representation: the latter is composed exclusively of phonic material. Finally, the model Bhatt \& Nikiema operate with is extremely complex: onset positions that are difficult to motivate are associated with coda positions while at the same time diffusing nasality to the vowel. Then, when the vowel has become nasalized, it spreads its nasality onto the coda. Since we associate nasality with vowels, not adjacent, floating, or unassociated consonants, our analysis doesn't run into this sort of problem.
} 
(15)

$\begin{array}{ll}\text { Segmental tier } & \\ \text { Root level } & \text { Nodes } \\ \text { (set of features) } & \text { [-cons] [+nasal] }\end{array}$

To support their claim Paradis and Prunet adduce empirical evidence from borrowing. They examined the incorporation of lexical items from donor languages exhibiting different types of nasal vowels into the phonological system of a single recipient language. They show that different patterns appear in the recipient language depending upon the nature of the nasal vowels in the donor language. If the nasal vowels are underlying in the donor language, and if the borrower language does not possess underlying nasal vowels, then they are unpacked in the borrower language, as is the case of the reproduction of French lexemes containing nasal vowels by speakers of Canadian English. If, on the other hand, they are not underlying, i.e., the product of nasal assimilation or spreading, then they appear in the recipient language as oral vowels, i.e., the set of features specifying the vowel quality without the nasality feature, as is the case in the reproduction of Malay lexemes by these same anglophone speakers. These data showing different outcomes according to the underlying value of the input suggest that there is a fundamental difference between underlying and assimilatory vocalic nasality (16). English borrowing

Malay (progressive nasalization)

[rami] 'type of fiber' [xami] / *[xamin] $]$ *[ramin] [nãpu] 'musk deer'

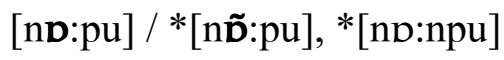

French (underlying nasality)

[amãdin] 'amandine' [æməndin]

[lãmas] 'in a group' [anmæs] 
3. Proposed analysis

There are three types of data involving V's in $\mathrm{HC}$ that any phonological analysis needs to account for:

(17) a. Obligatory nasalization:
i. $\left[\int \tilde{a} \mathrm{~m}\right]^{7}[*$ Jam] 'room'
ii. [3ãm] [*3am] 'leg'
iii. [lãme] 'sea'

b. Obligatory non nasalization

i. Final position: [pan] [*pãn] 'breakdown'

ii. Word-internal position: [kanif] [*kãnif] 'penknife'

c. Free variation: [len] [lẽn] 'wool', [fanal] [fãnal] 'lantern'

Accordingly, we divide this section in three parts corresponding to each of these three types of data but, as will become clear below, we need to subdivide the first type into two subcategories.

\subsection{Underlying nasal vowels}

It appears superficially that the examples in (17ai) and (17aii) should be derived from the same underlying structures and the operation of the same principles, but in fact they differ fundamentally. We deal first with cases of obligatory surface nasalization like [Jãm] [*]am] 'room'. These are handled by positing underlying V's with root nodes characterized in (15) above; these $\mathrm{V}$ 's occur in all environments, including before $\mathrm{N}$, and contrast with corresponding oral vowels (18).
a. [pã] 'peacock' versus [pa] 'step'
b. [pãt] 'slope' versus [pat] 'paste'
c. [mãti] 'lie' versus [mati] 'martyr'
d. [Jãm] 'room' versus [ [am] 'charm'

\footnotetext{
${ }^{7}$ Note that, unlike the corresponding lexeme in French, in HC this form never appears with the voiced stop /b/.
} 
3.2. Derived nasal consonants.

Bhatt and Nikiema (2000) describe in SLC a nasalization phenomenon involving the spread of nasality from left to right and from a V to a following oral consonant. This phenomenon, which affects underlying voiced stops forming the coda in the final syllable of root morphemes, also occurs in HC (19).
/3ãb/
(a) 3ãb+e 'to step over'
(b) 3ãm 'leg'
/vãd/ vãd $+\varepsilon z$ 'saleswoman' vãn 'to sell'
/lãg/ lãg + aj 'parlance, expression'
lay 'tongue'

In the form containing the derivational suffix /-aj/, (20a), the voice stop occurs in the onset of the syllable and it retains the features of the underlying form. However, as shown in (20b), in the root form the consonant is associated with the coda and attracts the nasality of the vowel. The nasal vowel spreads its nasality over the following segment that shares with it a position in the rime.

$$
\text { a. } \quad / \text { lãg+aj] } />\text { [lãgaj] }
$$

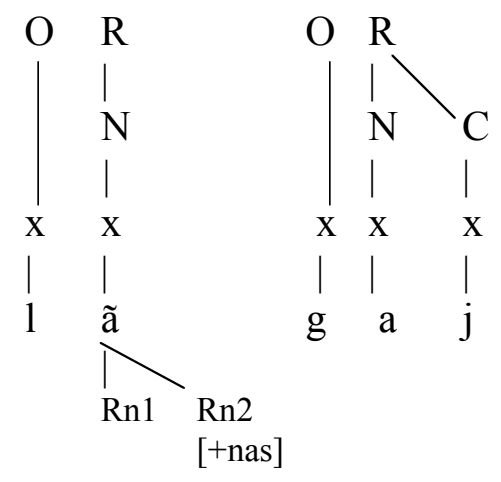

[lãgaj] 
b. $\quad /$ lãg/ $>$ [lãy]

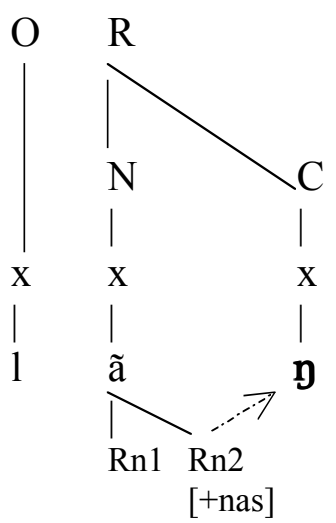

[lãy]

Thus, although the V's of [ [ãm] *[ $\left.\int \mathrm{am}\right]$ 'room' and [3ãm] *[3am] 'leg' appear identical at the surface level and both are underlying, the underlying structures from which they are derived differ: $\mathrm{CVN}$ for the former versus $\mathrm{CVC}$, where the coda has the feature specification $[+$ stop, + voice $]$ for the latter ${ }^{8}$. This type of alternation offers strong evidence for the existence of underlying nasal vowels, i.e., [+nas] can only be part of the feature specification of the vowel. In the root morpheme there isn't any floating [+nas] feature because in polysyllabic words the nasal feature does not spread leftward beyond the vowel, that is, /desãd/ yields only [desãn] and *[dẽsãn] or *[nẽsã] are excluded. Clearly, in the environment of underlying nasal vowels a progressive nasalization rule operates that is restricted within the rime and applies only to voiced obstruent segments. The coda consonant keeps its specification for place of articulation.

\subsection{Obligatory non-nasalization}

One major difference between $\mathrm{HC}$ and SLC is that in the latter creole surface sequences are absent in which an oral vowel occurs obligatorily before a N. Thus, matching HC [pan] 'breakdown' SLC shows free variation: [pan] [pãn]. The occurrence of lexemes containing obligatory $\mathrm{V}$ [-nasal] $\mathrm{N}$ sequences, in both morpheme-final and non-final syllables, as in (17b), provides additional support to our hypothesis of underlying V's; it also makes the application of the Bhatt \& Nikiema (2000) solution unworkable for HC.

\footnotetext{
${ }^{8}$ This phenomenon occurs widely in non-standard varieties of French: regional varieties, including those in the Americas (Louisiana, Saint-Bart, etc.) and so-called popular French. In the latter variety, which in fact characterizes everyday speech, a pronunciation such as [3ãm] for jambe is nearly categorical.
} 


\subsection{Optional nasalization}

We account for the different surface outputs of (17a-i) and (17c), namely obligatory versus optional nasalization, by deriving the former from underlying nasalization and the latter from an optional regressive assimilation rule. Variable forms, such as those of $(17 \mathrm{c})$ are derived as follows (21):

$\begin{array}{clllll}\text { (21) a. } & \mathrm{O} & \mathrm{N} & \mathrm{O} & \mathrm{N} & \mathrm{C} \\ & \mathrm{I} & \mathrm{x} & \mathrm{x} & \mathrm{x} & \mathrm{x} \\ & \mathrm{f} & \mathrm{a} & \mathrm{n} & \mathrm{a} & 1\end{array}$

[fanal]

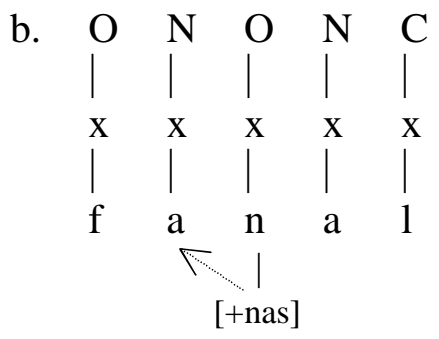

[fãnal]

In the context of nasal consonants forms so marked in the lexicon may undergo optional nasalization spreading leftward from an adjacent N. Another alternative, that we reject, is optional denasalization. First, the regressive assimilation hypothesis complies with the markedness requirements of Universal Grammar: nasalization of vowels morpheme internally in the context of $\mathrm{N}$ is unmarked. Second, arguing from a language internal perspective, Cadely (to appear-a) presents evidence that suggests that nasalization in lexical items showing the structure XCVNVX constitutes a marked feature. As mentioned in 2.2 above, such forms where the $\mathrm{V}$ is not nasalized before $\mathrm{N}$ are twice as numerous as those showing nasalization. In addition, by comparing current pronunciations with those that can be deduced from the spelling conventions of texts of the colonial period, a stage of the language that Valdman (1992) labels Saint-Domingue Creole, he shows that the frequency of nasalized forms increased since the formative period of HC. He also refers to an apparent linguistic change in progress noted first by Valdman (1991) involving the extension in nonnasal environments of nasal allomorphs of the definite determiner among bilingual speakers. To conclude, lexemes like [ [ãm] (17a) and [kanif] (17b) have underlying nasal and oral vowels, respectively, whereas those exhibiting free variation like [fanal] [fãnal] $(17 \mathrm{c})$ are marked in the lexicon to undergo optional regressive assimilation.

To be sure, there are considerable differences among speakers about which lexical items undergo optional nasalization and intra-speaker variation as well. Nonetheless, the situation in HC differs markedly from that reported by Bhatt \& Nikiema (2000) for SLC. 
Those native speakers we have consulted and the available lexicographic resources clearly identify lexemes where nasalization is not permitted.

\section{Nasalization in derivational morphology}

Another phenomenon involving the assimilation of nasalization in $\mathrm{HC}$ occurs in the derivation of denominal verbs by the adjunction of the verb forming suffix /-e/, the most productive affix in the language, see (4). Nasal assimilation spreading rightward from vowel to vowel across a morpheme boundary also occurs with the definite determiner (22):
a. bãk lã 'the bank'
b. bak la 'the tray'
kabãn nã 'the bed' chat la 'the cat'
pã ã
'the peacock'
pa a 'the step'

The outward similarity between the spreading of nasalization in (4) and (22) would lead one to postulate nasal harmony in which nasality spreads rightward from the nucleus of the root form to the suffix. However, this hypothesis runs afoul of the data in (23) where there is no spreading. These militate against vowel harmony:

$\begin{array}{llllll}\text { kõt }+\mathrm{e} & \text { 'account' } & > & \text { kõte } & \text { *kõtẽ } & \text { 'to count' } \\ \text { avãs }+\mathrm{e} & \text { 'advance' } & > & \text { avãse } & \text { *avãsẽ } & \text { 'to advance' } \\ \text { flãm }{ }^{9}+\mathrm{e} & \text { 'flame' } & > & \text { flãbe } & \text { *flãbẽ } & \text { 'to singe' } \\ \text { 3ãm }+\mathrm{e} & \text { 'leg' } & > & \text { 3ãbe } & { }^{*} \text { 3ãbẽ } & \text { 'to cross over' }\end{array}$

The absence of nasalization in the forms in (23) but its presence in those in (4) indicates that it is crucially dependent on the presence of a root-final N. However, as shown in (24) progressive assimilation of nasalization also occurs in lexemes ending with a $V$; the data are based on Freeman \& Laguerre (1998) ${ }^{10}$.

a. $\quad \mathrm{N}$ coda

i. Oral variant only

$$
\text { dwan 'customs' dedwane 'to clear through customs' }
$$

\footnotetext{
${ }^{9}$ Recall (3.2.) that the root form [flãm] is derived from /flãb/ and [3ãm] from /3ãb/.

${ }^{10}$ As would be expected, there is considerable variation among native speakers.
} 
ii. Variation

blãm 'blame' blame/blãmẽ 'to blame'

iii. Nasalized variant only

plim 'feather' deplimẽ 'to pluck (feathers)'

b. $\mathrm{V}$ final

i. Variation

padõ 'pardon' padone/ padõnẽ 'to pardon'

ii. Nasalized variant only

butõ 'button' butõnẽ 'to button'

c. $\quad \nabla$ final with vowel change

desẽ 'drawing' desine/ẽ 'to draw'

We provide a unified treatment for these derivatives based on positing a root morpheme-final underlying nasal vowel for the forms in (24b) and (24c). Because the affixation results in an empty onset slot, the nasality feature of the vowel is associated with the following syllable and surfaces as its onset. For the forms in (24a) the existing coda attaches to the following syllable to fill the empty onset slot. This analysis is motivated by the existence of forms like those in (25) not involving nasalization in which a glide is created to repair the formation of a hiatus caused by the affixation of the /-e/ suffix.
fizi 'gun'
fizije 'to shoot'
ãnwi 'trouble'
anwije 'to bother'
plãfe 'floor'
plã eje 'to lay a floor'

HC has available several hiatus filling strategies, one of which found in the northern dialect involves the insertion of the sonant /r/, e.g.[papa] 'father' ,/papa a mwẽ/ > [paparãm]'my father'. But the most favored repair strategy takes the form of glide creation $(26)^{11}$.

\footnotetext{
${ }^{11}$ As a general rule, the inserted segments remain high on the sonority scale.
} 


$\begin{array}{lll}\text { (26) } & \text { French } & \text { HC } \\ \text { océan } & \text { osejã } & \text { 'ocean' } \\ \text { théâtre } & \text { tejat } & \text { 'theatre' } \\ \text { poète } & \text { powèt } & \text { 'poet' } \\ \text { aorte } & \text { awòt } & \text { 'aorta' }\end{array}$

The [+nas] feature of both the coda $\mathrm{N}$ and that resulting from hiatus repair strategy spreads to the adjacent vocalic suffix. There remains the occurrence of free variation in the suffix and the puzzling case of the denasalization of the root morpheme final vowel in [padone] (24b-i) and [desine] (24c). The progressive assimilation is a feature whose optional or obligatory nature must be marked on particular root morphemes. It does not apply to forms like /dwan/ (24a-i); it is obligatory in forms like /butõ/ (24b-ii); and optional in all other cases, see the derivations of [blãmẽ] and [butõnẽ] in (27). As is the case for the optional assimilation rule (3.4.), empirical studies need to be undertaken for a description of the dialectal and/or sociolinguistic determinants of these lexical markings.

a. blãmẽ

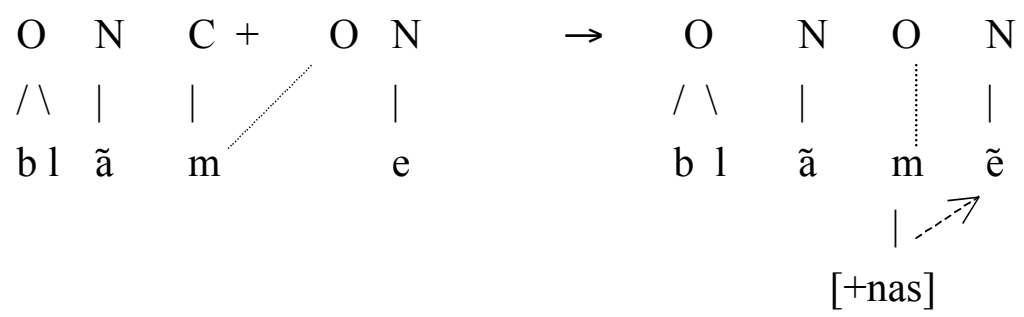

b. butõnẽ

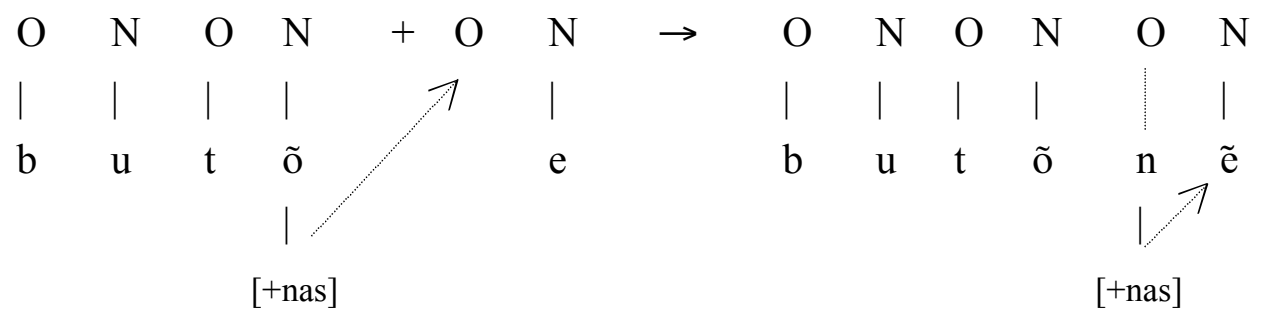

We explain the puzzling case of /padõ/ by hypothesizing that there are in $\mathrm{HC}$ two ways to fill the empty onset. In most instances, the nasal node delinks from the vowel position in order to fill the onset. Alternatively, it only spreads its [+nas] feature onto the empty onset, but still remains associated with the root node of the vowel. The two alternative 
derivations are indicated in (28). The application of one or the other of these two treatments appears be optional ${ }^{12}$.
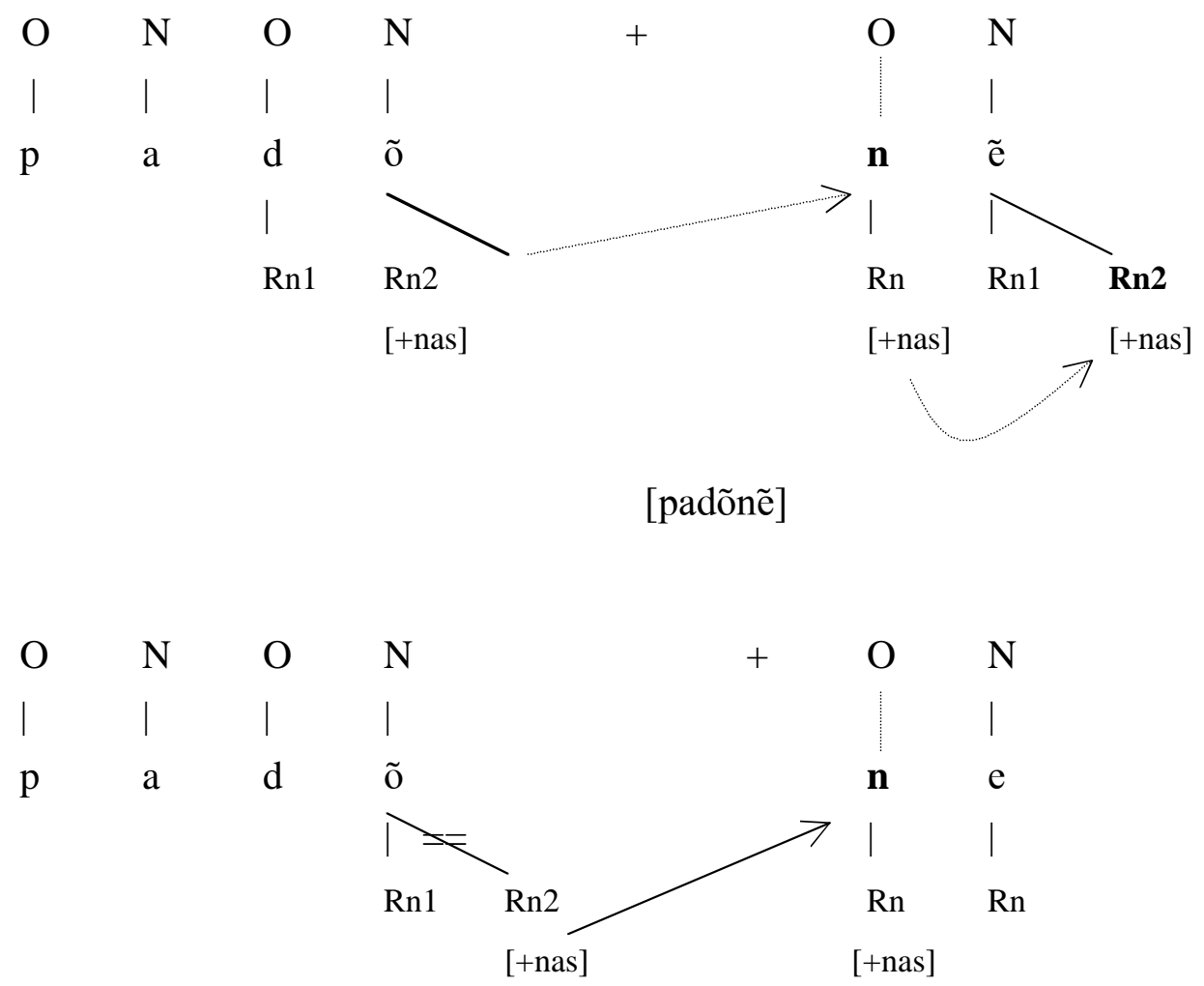

[padone]

association line

spreading line

As is the case for the regressive consonant to vowel assimilation treated in 3.4., the nasal assimilation rule applying to the suffix /-e/ needs to be constrained by lexical marking because it occurs only with that suffix. The nasality feature is not diffused across morpheme boundaries in the case of other vowel initial suffixes, for example: /tẽtẽ/'foolishness' > [tẽtẽnad] 'nonsense'; kõferãs/ 'lecture' > [kõferãsje] 'lecturer'; /Jifõ/ 'rag' > [ [ifõnje] 'dresser' (but [ jifõnẽ] 'to wrinkle'). The vowel change in [desine] (25c) involves a vowel quality change that we leave aside in this article.

\footnotetext{
${ }^{12}$ The vowel change in [desin e] (25c) involves a vowel adjustment rule that we leave aside in this paper.
} 


\section{Conclusion}

In this paper we have started from the traditional view that vocalic nasality is underlying in $\mathrm{HC}$, that is, V's must be indicated in the lexicon. A marked feature of $\mathrm{HC}$ is

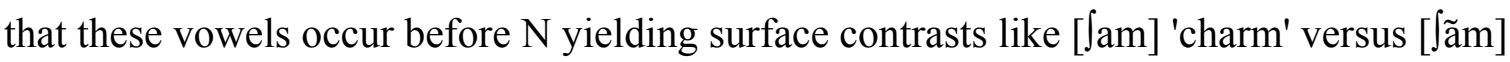
'room'. This proposal, which is consonant with theoretical assumptions of autosegmental phonology, also entails positing three different types of nasal assimilation processes: (1) vowel-to-consonant progressive assimilation operating rime internally that produced additional VN sequences: [flãm] </flãb/; (2) optional consonant-to-vowel regressive assimilation also morpheme internal operating within root morphemes: [lẽn] [lहn] 'wool', [fãnal] [fanal] 'lantern'; (3) consonant to vowel progressive assimilation rule operating across morpheme boundaries associated with onset creation to repair hiatus limited to the verb forming suffix /-e:/: [deplimẽ] </plim/'to pluck (feathers)', [blame / ẽ] > /blãm/'to blame', [padone/padõnẽ] </padõ/ 'to pardon'; this complex process is subject to extensive variation, most probably free (i.e. intra-speaker) variation.

A superficial review of our approach might suggest that it violates the Obligatory Contour Principle because in a surface form like [fãnal] it appears that the [+nasal] feature of the vowel is juxtaposed to a following $\mathrm{N}$ in a sequence VN. However in our analysis, following Paradis \& Prunet (2000), the $\mathrm{V}$ and the contiguous $\mathrm{N}$ are situated on separate tiers: the two segments are adjacent in the linear sequencing of segments but not at the level of root nodes.

Another distinguishing feature of our analysis is that the first and second processes are optional and autonomous and that they affect only previously marked lexical items. It appears that non-inherent nasality is an innovative feature of $\mathrm{HC}$. But the empirical basis of currently available descriptive studies of the language is not robust enough for us to hazard such a generalization.

It is no doubt the case that some sort of nasal assimilation, probably vowel harmony, and hiatus repair strategies also contribute to the puzzling allomorphy of the definite determiner, but the treatment of this complex problem is beyond the scope of this study. 
Finally, in an early treatment of HC nasal vowels Valdman (1970) distinguished between primary (underlying) and secondary (derived) nasality. He provided acoustic evidence that suggested that primary nasality corresponded to what Delattre (1967) termed nasality by cancellation (annulation) whereas secondary nasality showed the acoustic characteristics of nasality by damping (amortissement). For Delattre cancellation, involving the reduction of the first formant resulting by the formation of a velic cavity, yields maximally distinctive vocalic nasality. Damping, on the other hand, characterized by only the lowering of the velum, produced vocalic nasality that is more diffuse. But, currently, experimental phoneticians have discovered that nasality is much more complex than Delattre theorized and our preliminary attempts to duplicate Valdman's study (1970) have yielded inconclusive results.

\section{References}

Bhatt, Parth and Emmanuel Nikiema (2000): Le statut de la nasalité en créole de SainteLucie. - In: Revue québécoise de linguistique 28, 23-45.

Cadely, Jean-Robert (to appear-a): Le statut de la nasalité en créole haïtien.- In: Lingua (to appear-b): Nasality in Haitian Creole.

(1994): Aspects de la phonologie du créole haïtien. Unpublished doctoral dissertation, UQAM, Montréal.

Chaudenson, Robert (1992) : Des Iles, des hommes, des langues: langues créoles, cultures créoles. Paris: L'Harmattan.

d'Ans, Andre-Marcel (1968): Le créole français d'Haïti. La Haye: Mouton.

Dejean, Yves (1980): Comment écrire le créole d'Haïti. Outremont (Québec): Collectif Paroles.

Delattre, Pierre (1967): Divergences entre nasalités vocalique et consonantique.

Etienne, G. (1974): Le créole du Nord d'Haïti: Etudes des niveaux de structure. Unpublished dissertation: University of Strasbourg.

Freeman, Bryant and Jowel Laguerre (1998): Haitian-English dictionary. Lawrence: University of Kansas Institute of Haitian studies.

Goldsmith, John (1976): An overview of autosegmental phonology. - In: Linguistic Analysis 2, 23-68. 
Hall, Robert A., Jr. (1953): Haitian Creole: grammar-texts-vocabulary. Memoirs of the American Folklore Society 43.

Kaye, Jonathon; Lowenstamm, Jean and Jean-Roger Vergnaud (1990): Constituent structure and government in phonology. - In: Phonology 7, 193-231.

Mc Carthy, John (1988): Feature geometry and dependency: a review. - In: Phonetica 43, 84-108.

Paradis, Carole and Jean-Francois Prunet (2000): Nasal vowels as two segments: evidence from borrowings. - In: Language 76:2, 324-356.

Prunet, Jean-Francois (1992): Spreading and locality domains in phonology. New York:

Taylor, D. R. (1947): Phonemes of Caribbean Creole. - In: Word 3, 173-170.

Tinelli, Henri (1974): Generative and creolization processes: Nasality in Haitian Creole. - In: Lingua 33, 343-366.

Valdman, Albert, Pooser, Charles and Rozevelt Jean-Baptiste (1996): A learner's dictionary of Haitian Creole. Bloomington, Indiana: Indiana University Creole Institute.

Valdman, Albert; Yoder, Sarah; Roberts, Craig and Yves Joseph (1981): Diksyonne KreyolFranse, Angle (Haitian Creole-English-French dictionary). Bloomington, Indiana: Indiana University Creole Institute.

Valdman, Albert (1992): On the socio-historical context in the development of Louisiana and Saint-Domingue Creoles. - In: Journal of French Language Studies 2, 99-119.

(1991): Le parler du 'Peuple' haïtien dans la Construction d'une norme écrite du Créole. - In: Etudes Créoles. XIV.1,11-29.

(1981): Haitian Creole - English - French dictionary. Bloomington, Indiana: Indiana University Creole Istitute.

(1978): Le créole: structure, statut et origine. Paris: Klincksieck.

(1970): Nasalization in Creole French. - In: Proceedings of the sixth international congress of phonetic sciences (Prague 1967). Prague: Academia-Publishing House of the Czechoslovak Academy of Sciences. 967-71.

Vernet, Pierre and Bryant C. Freeman (1988): Dictionnaire préliminaire des fréquences de la langue créole haïtienne. Port-au-Prince: Centre de Linguistique Appliqué de l'Université d'Etat d'Haïti. 